\title{
DETERMINATION OF THE SUITABILITY OF OIL PALM FIBRE COMPOSITE FOR BUILDING APPLICATIONS BY CONE CALORIMETER AND THERMAL ANALYSIS
}

\author{
${ }^{*}$ Suoware, T. O., ${ }^{2}$ Edelugo, S. O., ${ }^{1}$ Amgbari, C. O. and ${ }^{1}$ Sorgbara, F. L.
}

\author{
${ }^{*}$ Department of Mechanical Engineering Technology, Federal Polytechnic, Ekowe, Bayelsa State \\ *Corresponding Author Email: Suoware.research@gmail.com Phone: +2347037201960 \\ ${ }^{2}$ African Centre of Excellence, ACE-SPED, University of Nigeria, Nsukka \\ Email: Sylvester.edelugo@unn.edu.ng Phone: +2347037463298
}

\begin{abstract}
The high yielding of oil pam fibre reinforced composite (OPFC) to fire has necessitated research to improve and develop fire retardants (FR) to mitigate the spread of fire. Researchers relied on Flame Retardants (FR) classified as either halogenated or non-halogenated based FR to improve the performance of composites with emphasis on flammability properties (FP). The main object of this paper is to evaluate the effect of six non-halogenated FR species in OPFC to meet required fire safety standards for building purposes. The six FR species comprising aluminum tri-hydroxide (ATH), ammonium polyphosphate (APP), Gum Arabic powder (GAP) and carbon black (CB) were processed with OPFC at 0,15 and 18\% loading ratio using hand lay-up compression moulding technique. Specimens cut from the OPFC panels were tested for flammability and thermal properties using thermogravimetric analysis (TGA/DSC Metlar Toledo) and cone calorimeter apparatus respectively. The result obtained for thermal analysis shows that the panel was thermally stable at $391.6 \mathrm{OC}$ before degradation began compared to those without FR while peak flammability properties obtained for heat released rates, mass loss rates and smoke production rates showed the OPFC panels rapid fire response were significantly reduced respectively by $67.4 \%, 50.9 \%$ and $37.5 \%$ compared to those without FR. It can be concluded that the hybrid FR comprising APP-GAP showed a stable char structure during fire and thus prevented the escape of combustible volatiles which reduced the peak FP values of the OPFC panels. These flammability properties could be said to meet required fire safety standards for building applications.
\end{abstract}

Keywords: ammonium polyphosphate, flammability properties, flame retardants, gum arabic, oil palm, fibre, thermal stability

LICENSE: This work by Open Journals Nigeria is licensed and published under the Creative Commons Attribution License 4.0 International License, which permits unrestricted use, distribution, and reproduction in any medium, provided this article is duly cited.

COPYRIGHT: The Author(s) completely retain the copyright of this published article.

OPEN ACCESS: The Author(s) approves that this article remains permanently online in the open access (OA) mode.

QA: This Article is published in line with "COPE (Committee on Publication Ethics) and PIE (Publication Integrity \& Ethics)". 


\section{INTRODUCTION}

In the world of composites, fibres obtained from natural sources are becoming very attractive for non-structural building applications probably because of their huge benefits which includes but not limited to low-cost, abundant availability, lightweight, environmental benign and biodegradability as reported by Layth et al., (2015). Natural fibres (NF) such as jute, sisal, hemp, flax, kenaf, sugarcane, banana, oil palm, coir, wood etc. are naturally grown. They consist of organic constituents which make up cellulose, hemicellulose and lignin and are usually called lignocellulosic or cellulosic fibres. NF derives its strength and rigidity from cellulose that is semi-crystalline polysaccharide in nature. Cellulose-based fibres obtained from plants are broadly used in polymer composites due to their abundance and renewability within a short time when compared to animal or mineral sources as reported by Layth et al., (2015).

Oil Palm (Elaeis guineensis) with abundant production rate in Nigeria is regarded as huge amount of lignocellulosic waste and un-utilized. The waste from oil palm constitutes environmental nuisance which can be readily turned into valued-added products such as oil palm fibre reinforced polymer composite (OPFC) panels to meet various building needs. Oil palm fibre (OPF) is hard and tough but comes with a great challenge to overcome, their high susceptibility to flame when exposed to heat. The cellulosic content at $65 \%$ in OPF as reported by Suoware $e t$ al., (2017) on flammability of flame retarded natural fibre composites shows that OPF when compared to other fibres will generate higher flammability risk. In addition, it is important to note that the polymer matrix is the primary source of flammable volatiles that consist of a complex mixture of gases and solid particulates from incomplete combustion. Hence, to reduce the flammability risk of the oil palm composite panels to meet current fire safety standards for various building applications, flame retardants (FR) are usually added to the panels during fabrication.

Flame retarded OPFC panels can be manufactured either by incorporating halogenated based or halogenated free of FR as well as a lignocellulosic fibre bonded by polymer matrix to obtain lightweight panels through different processing techniques as reported by Marjavaara et al., (2009) and Virk et al., (2012). The panels can be used for building interiors to delay the start and spread of fire. Recent studies have shown that FR such as aluminum trihydroxide (ATH) and ammonium polyphosphate (APP) are considered the most favourable FR in polymers because they are greener, highly effective and of low toxicity as reported by Subastinghe et al., (2014), Yeonhae et al., (2013), Suoware et al., (2017) and Arjmandi. Kim et al., (2014) studied the effect of a commercially available ATH on the flammability and smoke intensity properties of kenaf and oil palm fibre reinforced composites and obtained promising results. Ertugrul et al., (2017) studied the effect of APP in combination with graphite in FR wood-polypropylene composite, the flammability properties (FP) obtained also showed some level of improvements. Other reports by Amina and Hassabo (2015), Gaelle et al., (2013), Ricciardi et al., (2012) and Hapuarachch (2009) also show that the combination of FR can achieve appreciable level of flame retardation.

The study of the fire behavior of OPFC panels has not been given the desired attention as seen from research works carried out using industrial and agricultural waste to produce particleboards and ceiling boards in Nigeria by Ikubanni et al., (2018), Obam (2010) and Suoware et al., (2019). In order to understand how effective, the FR on the fire behaviour and subsequently improve on the reaction to fire properties to meet required fire safety standards for building application. The APP was modified with gum Arabic powder (GAP) to form new intumescent FR species 
and then hybridized with ATH along with a synergist carbon black (CB). The main objective in this paper is to develop and examine the FR effect on the flammability and thermal behaviour of oil palm composite panel.

\section{MATERIALS AND METHODS}

The testing of the OPFC panels was done at the Fire laboratory, University of Edinburgh, Scotland from January 2017 to April, 2017. First the samples; oil palm fibre were washed with n-Hexane to further remove impurities and treated with $5 \% \mathrm{NaOH}$ to improve the compatibility of the fibres with the polyester resin. These were then sun dried for 3 days to remove moisture content. A wooden mould measuring $(887.5 \times 510 \times 10) \mathrm{mm}$ was used to prepare the test specimens for different test protocols according to ASTM E 1354. The internal area of the mould was applied with Vaseline for easy removal before oil palm fibres (OPF) were randomly inserted into the mould. A paste of FR poured over the OPF comprised of ATH with a chemical formula $\left[\mathrm{Al}_{2}(\mathrm{OH})_{3}\right]$ of particle size $10 \mu \mathrm{m}$, APP with a chemical formula $\left[\left(\mathrm{NH}_{4} \mathrm{PO}_{3}\right) \mathrm{n}(\mathrm{OH})_{2}\right]$ a white-free flowing powder soluble in $\mathrm{g} / 100 \mathrm{ml}$ of $\mathrm{H}_{2} \mathrm{O}$ with average particle size of $15 \mu \mathrm{m}$, gum Arabic (GAP) and carbon black (CB). Six FR species as shown in table 1 were added to the total amount of polyester resin at 0,12,15 and $18 \%$ loading ratio. The OPFC panels were produced using hand lay-up compression moulding technique and cured at room temperature. The required quantities of the fibres and polyester resin used to produce the panels were obtained as shown in Equ.1.

$$
V_{f}=\frac{M_{f} / \rho_{m}}{\left(M_{f} / \rho_{m}\right)+\left(1-M_{f}\right) \rho_{m}}
$$

Table 1: Formulation of flame retardant loadings in the fabricated composite panels

\begin{tabular}{|c|c|c|c|c|}
\hline \multirow[t]{2}{*}{ Specimen ID } & \multirow{2}{*}{$\begin{array}{l}\text { OPF/Resin Ration } \\
\text { (wt. \%) }\end{array}$} & \multicolumn{3}{|c|}{$\%$ of FR Formulations* } \\
\hline & & ATH & APP/GAP (2:1) & CB \\
\hline $\mathrm{OPFC}_{0 \%}$ & $10 / 90$ & - & - & - \\
\hline $\mathrm{X}_{0}: 12 \%$ ATH & $10 / 90$ & 12 & - & - \\
\hline $\mathrm{Y}_{0}: 12 \%$ APP-GAP & $10 / 90$ & 12 & - & - \\
\hline $\mathrm{Z}_{0}: 15 \% \mathrm{ATH} / \mathrm{CB}$ & $10 / 90$ & 9 & - & 6 \\
\hline $\mathrm{X}_{1}: 15 \%$ APP-GAP/CB & $10 / 90$ & - & 9 & 6 \\
\hline $\mathrm{Y}_{1}: 18 \%$ ATH/APP-GAP & $10 / 90$ & 9 & 9 & - \\
\hline 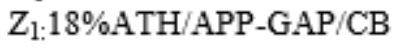 & $10 / 90$ & 9 & 6 & 3 \\
\hline
\end{tabular}

*Formulation of flame retardant specified in percentage relative to the total amount of resin

[ATH: Aluminium Tri-hydroxide, APP: Ammonium polyphosphate, GAP: Gum Arabic powder, CB: Carbon black] 


\section{EXPERIMENTAL METHODS}

Specimens cut from the OPFC were tested for thermal stability using thermogravimetric analysis (TGA/DSC 1; Metller Toledo analyzer) at the University of Edinburgh as well as for flammability properties using the cone calorimeter apparatus by PL thermal sciences located in the fire laboratory of university of Edinburgh, Scotland.

\section{THERMAL ANALYSIS}

$5 \mathrm{~g}$ of OPFC samples were collected and then heated for $10 \mathrm{~min}$ at $105^{\circ} \mathrm{C}$ under nitrogen gas (N2) to determine moisture content; the temperature was then raised at $25^{\circ} \mathrm{C}$ min- 1 to $900^{\circ} \mathrm{C}$ where it remained for a further $10 \mathrm{~min}$ to determine volatile matter content. Finally, air was introduced to the system combusting the sample (also at $900^{\circ} \mathrm{C}$ ) for 20 minutes in order to determine the ash content. Fixed carbon is calculated on a weight percent basis by subtracting moisture, volatile matter and ash values from the original starting mass.

\section{CONE CALORIMETER}

The specimen were also tested for flammability properties such as ignition time (Tig), peak HRR (HRRp), average HRR (HRRavg), total heat released (THR), effective heat of combustion (avg-Ehc), mass loss rate (MLRp), specific MLR (SMLRavg), residual mass (Rm), smoke production rate (SPRavg), total smoke released (TSR), specific extinction area (avg-SEA), carbon monoxide production (COP) using the cone calorimeter apparatus. The specimens $(100 \times 100 \times 10) \mathrm{mm}$ was wrapped in aluminum foil; along the side and bottom to reduce heat losses. The specimens were inserted in a sample holder and then placed on the load cell which measures the specimen mass loss in real time as combustion takes place. The specimens were exposed in the horizontal orientation at heat flux of $50 \mathrm{~kW} / \mathrm{m}^{2}$. An electric truncated cone shaped heater causes thermal decomposition and release pyrolysis products from the specimen surface. The height between the cone heater and the surface of the specimen is maintained at $25 \mathrm{~mm}$. Ignition is produced by an intermediate piloted spark igniter located above the specimen and removed when the pyrolysis products ignites. The process was repeated multiple times and a sensible result was recorded. 


\section{RESULTS}

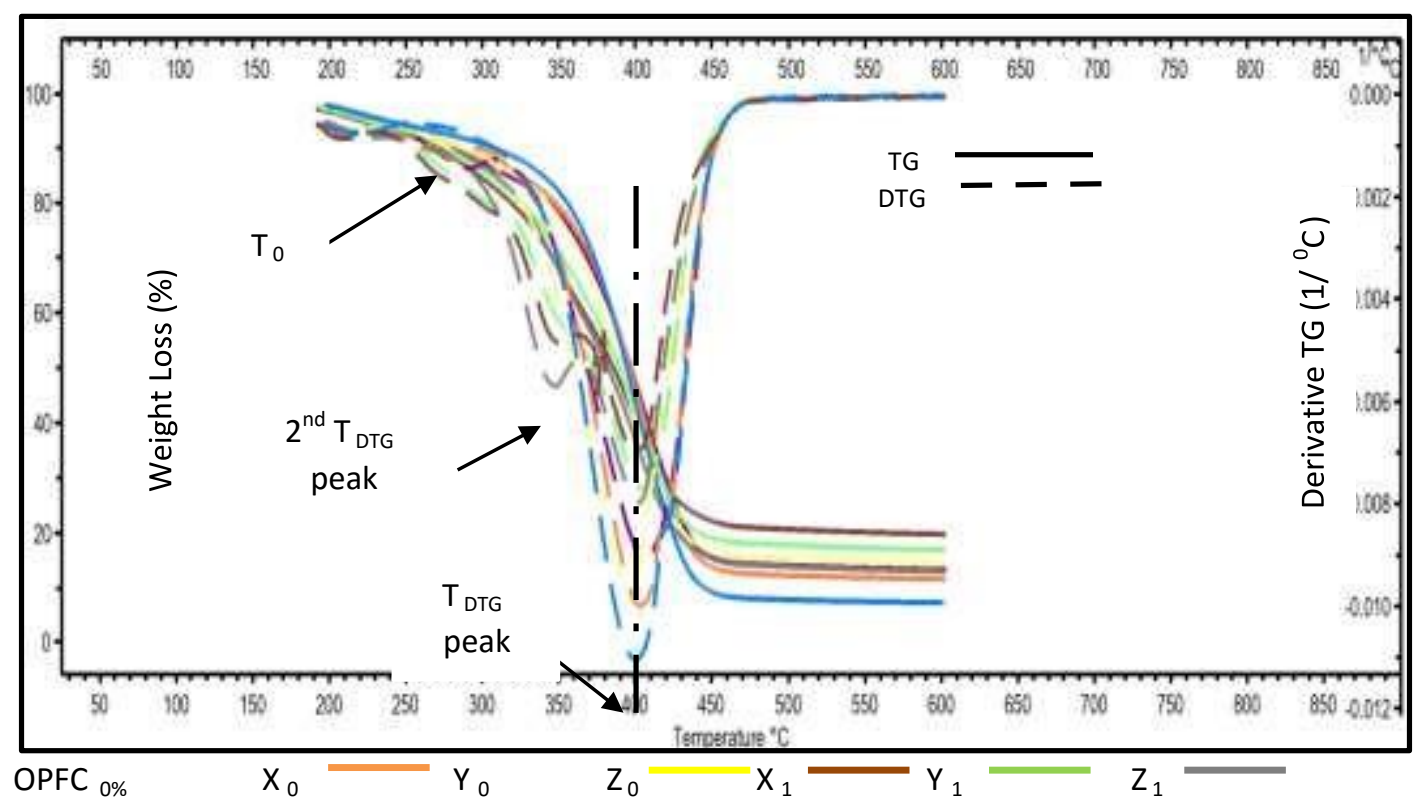

Figure 1: Thermogravimetric analysis (TGA) and derivative of thermogravimetric (DTG) curves of various flame retardant formulations in OPFC panel 

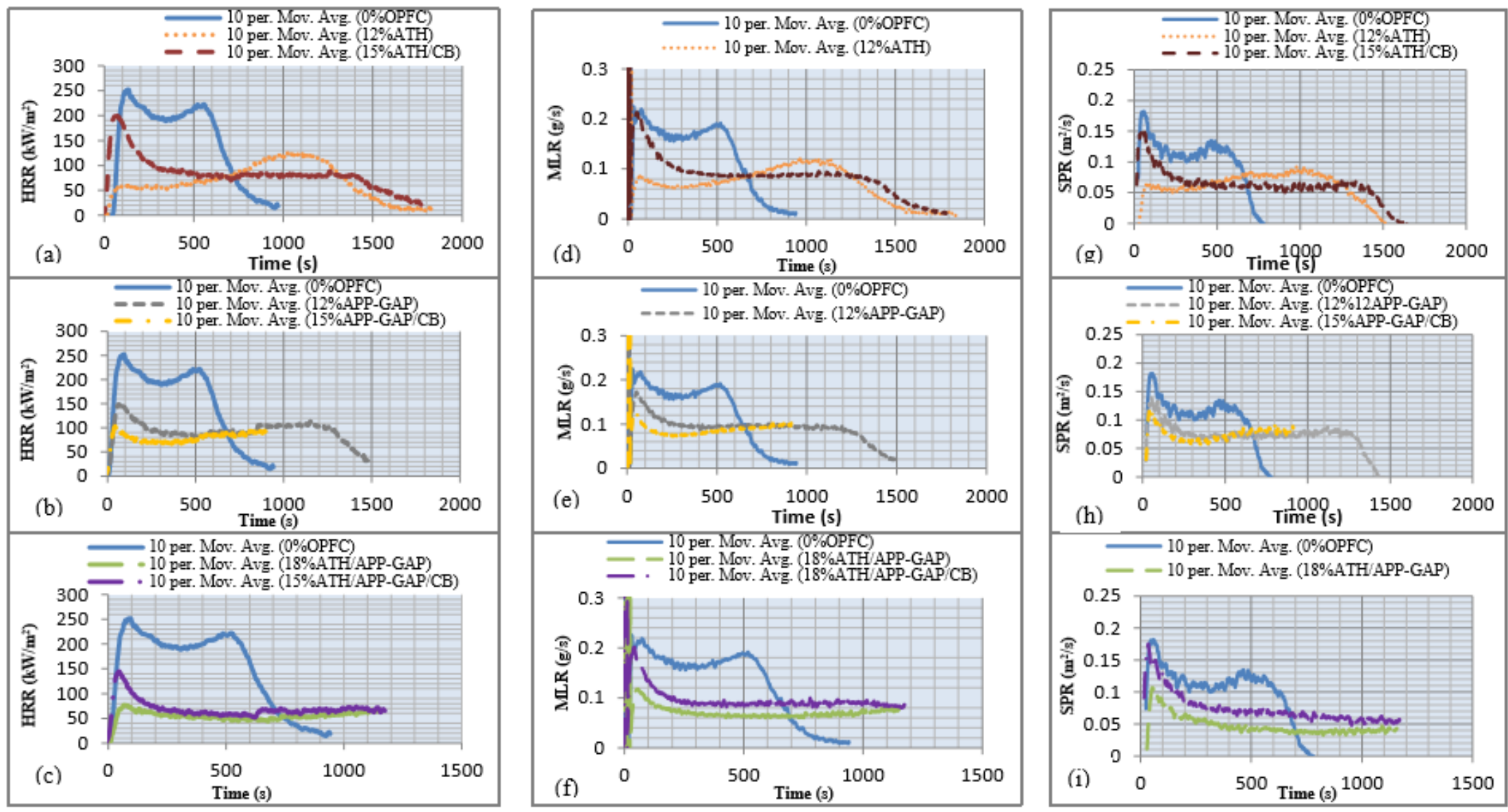

Figure 2: Comparison of the OPFC $0 \%$ panel with the FR formulation panels: (a-c) Heat release Rate, HRR (d-f) Mass Loss rate, MLR and (g-i) Smoke Production Rate, SPR at $50 \mathrm{~kW} / \mathrm{m}^{2}$ Heat Flux 


\section{DISCUSSIONS}

\section{THERMAL STABILITY}

In Fig 1, the sigmodal shaped TGA curves revealed the FR exhibited a typical single WL degradation. It also shows that the $X_{0}$ and $X_{1}$ species in the OPFC panel exhibited better thermal stability as initial decomposition ( $\mathrm{T}_{0}$ ) began respectively around $376.3^{\circ} \mathrm{C}$ and $391.6^{\circ} \mathrm{C}$ which improved by $5.1^{\circ} \mathrm{C}$ and $20.48^{\circ} \mathrm{C}$ respectively higher when compared to the $\mathrm{OPFC}_{0 \%}$ panel at $371^{\circ} \mathrm{C}$ whereas the other $\mathrm{FR}$ deteriorated. This improvement could be caused by the constituents of oil palm fibre comprising cellulose of $65 \%$ and lignin of $29 \%$. Lignin decompose early to form char that slow thermal decomposition. The $Y_{0}$ and $Y_{l}$ panels exhibited the least thermal stability however implies that the FR decomposed early which is an indication of a good flame retardant as its early decomposition could trap the escape of combustible volatiles longer. The initial WL through to the end of the decomposition process falls within the temperature of $\left(371^{\circ} \mathrm{C}-442^{\circ} \mathrm{C}\right)$ which agrees with the study of other researchers Dhandapani et al., (2016) and Aisyah et al., (2019) on OPEFB reinforced in bio- based polyester composite. Further thermal decomposition beyond $\mathrm{T}_{0}$ to $900^{\circ} \mathrm{C}$ indicating the end of the test showed the $X_{I}$ formulation of APP-GAP in the OPFC panel produced the highest char residue of $17.4 \%$ compared to OPFC $0 \%$ panel at $6.15 \%$. The $X_{0}$ and $X_{I}$ panels were fully degraded around $421.9^{\circ} \mathrm{C}$ and $426.9^{\circ} \mathrm{C}$ respectively higher than those without $\mathrm{FR}$ at $409.8^{\circ} \mathrm{C}$.

\section{FLAMMABILITY PROPERTIES}

The HRR, MLR and SPR profile depicted in (Fig 2) shows that shortly after ignition, a sharp rise and then a sudden decline were observed this indicates the activities of combustibles gases during combustion. The broader appearance which stayed at a lower profile throughout the burning process suggests that the FR is interacting with the combustible products by oxidation starvation. This is also a typical characteristic of a char residue-forming material and confirms the role the lignocellulosic content the fibre played in the formation of char during combustion as reported by Mohammed et al., (2020) and Haitang et al., (2020). Besides, the last part of the HRR curves represents glowing combustion of the char residue at solid state interface (where volatiles have been burnt out) as reported by White $e t$ al., (2011). It was observed that $Y_{l}$ in the OPFC panel exhibited outstanding performance and consistency as it enhanced the entire flammability properties $(\mathrm{FP})$. The FP were Tig $=20 \mathrm{~s}, \mathrm{HRRp}=86.6 \mathrm{~kW} / \mathrm{m}^{2}, \mathrm{HRRavg}=55.8 \mathrm{~kW} / \mathrm{m}^{2}$, $\mathrm{THR}=36.7 \mathrm{MJ} / \mathrm{m}^{2}, \mathrm{MLRp}=0.131 \mathrm{~g} / \mathrm{s}$, SMLRavg $=7.1 \mathrm{gs}^{-1}, \mathrm{Rm}=54.6 \%$, avg-Ehc $=8 \mathrm{MJ} / \mathrm{Kg}$, SPRavg $=0.05 \mathrm{~m}^{2} / \mathrm{s}$, $\mathrm{TSR}=2447.7 \mathrm{~m}^{2} / \mathrm{m}^{2}$, avg-SEA $=666.5 \mathrm{~m}^{2} / \mathrm{Kg}$ and $\mathrm{COP}=0.035 \mathrm{Kg} / \mathrm{Kg}$ more those without FR $\left(\mathrm{OPFC}_{0} \%\right)$ at $\mathrm{Tig}=17 \mathrm{~s}$, HRRp $=265.5 \mathrm{~kW} / \mathrm{m}^{2}$, HRRavg $=150.2 \mathrm{~kW} / \mathrm{m}^{2}, \mathrm{THR}=49.6 \mathrm{MJ} / \mathrm{m}^{2}, \mathrm{MLRp}=0.267 \mathrm{~g} / \mathrm{s}$, SMLRavg $=14.4 \mathrm{gs}^{-1}, \mathrm{Rm}=$ $8.2 \%$, avg-Ehc $=12.7 \mathrm{MJ} / \mathrm{Kg}$, SPRavg $=0.08 \mathrm{~m}^{2} / \mathrm{s}$, TSR $=2733.7 \mathrm{~m}^{2} / \mathrm{m}^{2}$, avgSEA $=671.5 \mathrm{~m}^{2} / \mathrm{Kg}$ and $\mathrm{COP}=$ $0.066 \mathrm{Kg} / \mathrm{Kg}$. this indicates the hybrid FR was effective in reducing the release of combustible volatiles and could meet current fire safety standards for building applications.

\section{CONCLUSIONS}

From the thermal stability analysis, it can be concluded that the panels did not exhibit any significant change when FR were added as early degradation was observed. However, the $Y_{l}$ panel exhibited outstanding performance in delaying the early start of decomposition due to the decomposition mechanism of ATH/APP-GAP. The panel was 
thermally stable at $391.6^{\circ} \mathrm{C}$ before degradation began compared to $\mathrm{OPFC}_{0 \%}$ at $371.2^{\circ} \mathrm{C}$ and was fully degraded at $426.9^{\circ} \mathrm{C}$ compared to $\mathrm{OPFC}_{0 \%}$ at $409.8^{\circ} \mathrm{C}$. At $900^{\circ} \mathrm{C}$ which signifies the end of the test, the highest char residues were observed for $X_{1}$ at $17.4 \%$ more than those without FR, confirming APP-GAP to be a good flame retardant. From the FP, it concludes that the $Y_{I}$ panel slowed better the combustion process leading to outstanding performance of the entire flammability properties that could meet current fire safety standards. The peak HRR observed for $Y_{1}$ panel indicates the intensity of fire and how grows was drastically reduced by $67.4 \%$ and the average HRR which is a more reliable measure of contribution to sustained fire was reduced by $62.8 \%$.

\section{ACKNOWELDGEMENT}

The authors would like to appreciate Tertiary Educational Trust fund (Tet fund), Nigeria through grant approval. African Centre of Excellence, ACE-SPED, University of Nigeria, Nsukka for their support and the management of Federal Polytechnic Ekowe for its travel approval and the technical staff of the Rushbrook Fire facility, John Mul Building, University of Edinburgh, Scotland United Kingdom. 


\section{REFERENCES}

Arjmandi, R., Ismail, A., Hassan, A., Abu Bakar, A. (2017). Effects of Ammonium Polyphosphate Content on

Mechanical, Thermal and Flammability Properties of Kenaf/Polypropylene and Rice Husk/Polypropylene Composites. Construction and Building Materials, $152, \quad 484-\quad 493$ https://doi.org/10.1016/i.conbuildmat.2017.07.052

Aisyah H.A., Paridah, M. T., Sapuan, S. M., Khalina, A., Berkalp, O. B., Lee, S. H., Lee, C. H., Nurazzi, N. M., Ramli, N., Wahab, M. S., and Ilya, R. A. (2019). Thermal Properties of Woven Kenaf/Carbon Fibre-Reinforced Epoxy Hybrid Composite Panels. International Journal of Polymer Science https://doi.org/10.1155/2019/5258621

Amina, M. and Hassabo, H. (2015). Flame Retardant of Cellulosic Materials and Their Composites Polymer Blends pp: 247-314 DOI: 10.1007/978-3-319-03467-6-10

Dhandapani, S., Nayak, S. K., Mohanty, S. (2016). Surface Modification of Oil Palm Empty Fruit Bunch and Fiber Reinforcement Effect on Bio-Based Polyester Matrix Composites: Dynamic, Morphology, Thermal and Mechanical Properties" Journal of Elastomers and Plastics, 148(5): 456-479. https://doi.org/10.1177/0095244315580458

Ertugrul, A., Karaogul, E. and Mehmet, A. (2017). Effects of Fire Retardants on the Fire, Thermal and Mechanical Properties of Wood Plastic Composite using Recycled Fibre Kastamonu University Orman Fakutesi Dergisi, Journal of Forestry Faculty 17 (2): 334-342 doi.org/10.174557/kastorman.329427

Gaelle D., Elkacem, B., Taguet, A., Ferry, L. and Lopez-Cuesta, J. M. (2013). Improvement of the Behavior of poly (1,4-butanediol succinate)/flax Biocomposties by Fiber Surface Modification with Phosphorus Compounds: Molecular versus Macromolecular Strategy Polymer International 63(9)665-1673

Hapuarachch, T. D. and Peijs, T. (2009). Aluminium Tri-hydroxide in Combination with Ammonium Polyphosphate as Flame Retardants for Unsaturated Polyester Resin” EXPRESS Polymer Letters, 3(11) 743-751 https://doi.org/10.3144/expresspolymlett.32009.92

Haitang, Y., Yu, B., XU, X., Bourbigot, S., Wang, H. and Song, P. (2020) Lignin-Derived Bio-Based Flame Retardants toward High-Performance Sustainable Polymeric Materials. Green Chemistry, 22, 219-2161 https://doi.org/10.1039/DPGC00449A

Ikubanni, P. P., Adeleke, A. A., Adediran, A. A. and Agboola, O. O. (2018). Physico-Mechanical Properties of Particleboards Produced from Locally Sourced Materials. International Journal of Engineering Research in Africa. 39(1)112-118.

Kim, Y.T, Tan, H. J., Poisim, K. and Hoque, M. D. E. (2014) Flammability and Smoke Density of Kenafand Oil Palm Fibre Composites" International conference Symposium on advanced polymeric materials at PWTC, Kuala Lumpur Malaysia.

Layth, M., Ansari, M. N. M., Grace, P., Mohammad, J. and Saiful-Islam, M. (2015). A Review on Natural Fiber Reinforced Polymer Composite and Its Applications. Internal Journal of Polymer Science https://doi.org/10.1155/2015/243947 
Mohammed, A., Mohd, T. P., Chandrasekar, M., Shahroze, R. M., Jawaid, M., Nasir, M. and Siakeng, R. (2020)

Thermal Stability of Natural Fibers and their Polymer Composites Iran Polymer Journal 29, 625-648 https://doi.org/10.1007/s13726-020-00824-6

Obam, S.O. (2010) Properties of Sawdust, Paper and Starch Composite Ceiling Board American journal of scientific and industrial research ISSN: 2153-649X, 300-304 https://doi.org/10.5251/ ajsir.2012.3.5.300.304

Ricciardi, M., V. Antonucci, M. Giordano, M. and Zarrelli, M. (2012). Thermal Decomposition and Fire Behavior of Glass Fiber-Reinforced Polyester Resin Composites Containing Phosphate-Based Fire-Retardant Additives" Journal of Fire Sciences, 30(4), pp.318-330. https://doi.org/10.1177/0734904112439293

Suoware T.O., Edelugo S.O. and Ezema I.C (2017). Flammability of Flame Retarded Natural Fibre Composites and Application in Automobile Interior: A Review International Journal of Interdisciplinary Research (IJIR) 8(1) 2454-1362.

Subastinghe, A. and Bhattacharya, D. (2014) Performance of Different Intumescent Ammonium Polyphosphate Flame Retardants in PP/Kenaf Fibre Composites Composites Part A, 65, 91-99. https://doi.org/10.1o16/i.compositesa.2014.06.001

Suoware, T. O. and Edelugo, S. O. (2018). Thermal, Mechanical and Flame Spread Properties of Hybridized Flame Retardant in oil palm fibre-polyester panel. Springer Nature Applied Science; $1 ; 42$ https://doi.org/10.1007/s42452-018-0048-1

Suoware, T.O., Edelugo, S.O., Ugwu, B. N., Amula, E. and Digiteme, I. E. (2019). Development of Flame Retarded Composite Fibreboard for Building Applications using Oil Palm Residue. Materials de Construccion, Vol 69 (335) https://doi.org/10.3989/mc.2019.10418

Virk, A.S., Hall, W. and Summerscales, J. (2012). Modulus and Strength Prediction for Natural Fibre

Composites Material Science and Technology Vol 28, (7) https://doi.org/10.1179/1743284712Y.0000000022

White, J.E., Catallo, W.J., Legendre, B.L., (2011). Biomass Pyrolysis Kinetics: A Comparative Critical Review with Relevant Agricultural Residue Case Studies. Journal Analytical. Applied. Pyrolysis, 91 (1) pp 1-33 https://doi.org/10.1016/i.jaap.2011.01.004

Yeonhae, W and Donghwan, C. (2013) Effect of Aluminum Tri-hydroxide on Flame Retardancy and Dynamic Mechanical and Tensile Properties of Kenaf/poly(lactic acid) Green Composites. Advance Composite Materials 22(6), 451-464. DOI: 10.1080/09243046.2013.843831 